\section{Radiation-Induced Myocardial Injury Detected on Computed Tomography Myocardial Perfusion Imaging}

Yumi Hirota, MD; Keishi Moriwaki, MD, PhD;

Tairo Kurita, MD, PhD; Masaaki Ito, MD, PhD; Kaoru Dohi, MD, PhD

\section{A} 69-year-old woman was referred to hospital due to exertional dyspnea. She had history of partial mastectomy followed by hormone therapy and radiation therapy for left breast cancer 3 years earlier. Radiation therapy was delivered through tangential photon beams with a total dose of $50 \mathrm{~Gy} / 25 \mathrm{fr}$ using opposing bilateral portal irradiation for residual breast cancer. On admission, laboratory tests showed elevated troponin I of $19.3 \mathrm{ng} / \mathrm{mL}$ (normal, $<15.6 \mathrm{ng} / \mathrm{mL}$ ) and brain natriuretic peptide of $49.3 \mathrm{pg} / \mathrm{mL}$ (normal, $<18.4 \mathrm{pg} / \mathrm{mL}$ ). Transthoracic echocardiography showed preserved left ventricular (LV) ejection fraction without segmental asynergy, and moderate pericardial effusion. Positron emission tomography/computed tomography (PET/CT) demonstrated ${ }^{18} \mathrm{~F}$-fluorodeoxyglucose (FDG) uptake especially at the LV apex. Although CT angiography showed no coronary artery stenosis, adenosine-stress dynamic CT myocardial perfusion imaging (CTP) indicated reduced myocardial perfusion at the LV apex, in the same location as the FDG uptake region, which corresponded to the past irradiated field (Figure). Accordingly, the patient was ultimately diagnosed with radiation-induced myocardial injury (RIMI).

To the best of our knowledge, this is the first report of RIMI detected on CTP. CTP costs less, and has higher spatial resolution than single-photon emission CT, and is not contraindicated for patients with cardiovascular implanted electronic devices. ${ }^{1}$ Furthermore, CTP can simultaneously evaluate the recurrence of malignant tumor and RIMI in a single examination. This suggests that CTP may be a useful diagnostic tool for RIMI.

\section{Disclosures}

The authors declare no conflicts of interest.

\section{Reference}

1. Seitun S, De Lorenzi C, Cademartiri F, Buscaglia A, Travaglio $\mathrm{N}$, Balbi $\mathrm{M}$, et al. CT myocardial perfusion imaging: A new frontier in cardiac imaging. Biomed Res Int 2018; 2018: 7295460.

Received May 24, 2019; revised manuscript received July 25, 2019; accepted August 6, 2019; J-STAGE Advance Publication released online September 5, 2019 Time for primary review: 18 days

Department of Cardiology and Nephrology, Mie University Graduate School of Medicine, Tsu, Japan

Mailing address: Keishi Moriwaki, MD, PhD, Department of Cardiology and Nephrology, Mie University Graduate School of Medicine, 2-174 Edobashi, Tsu 514-8507, Japan. E-mail: kmoriwaki@ clin.medic.mie-u.ac.jp

ISSN-1346-9843 All rights are reserved to the Japanese Circulation Society. For permissions, please e-mail: cj@j-circ.or.jp
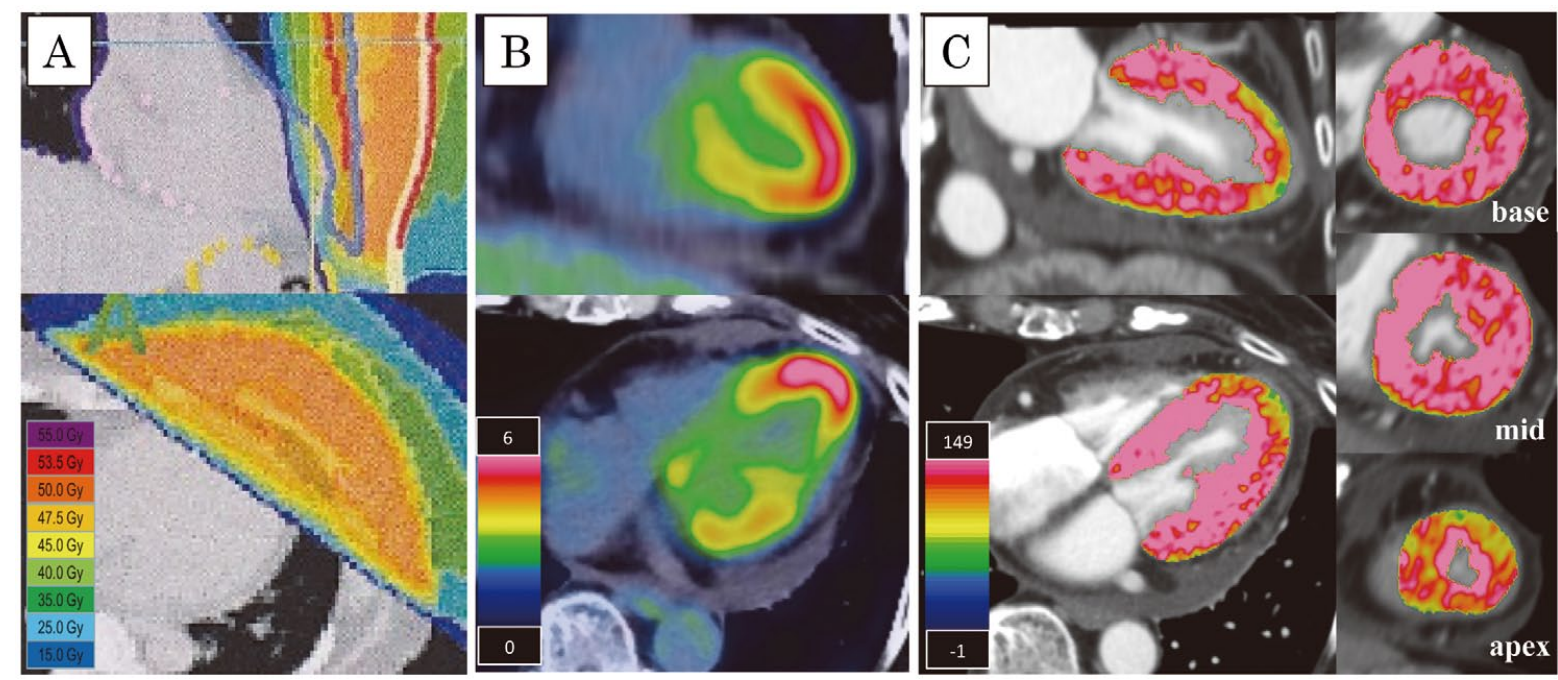

Figure. (A) Radiation fields and dose distribution for residual breast cancer in (Upper) coronal view and (Bottom) axial view. Both (B) ${ }^{18}$ F-fluorodeoxyglucose uptake and $(\mathbf{C})$ reduced myocardial perfusion on computed tomography myocardial perfusion imaging (CTP) correspond to the irradiated field. (C, Right side) Short-axis view of the left ventricle at the (Upper) base, (Middle) midsection, and (Bottom) apex on CTP. 